\title{
Dose Optimization for Single Intradiscal Administration of the Tumor Necrosis Factor- $\alpha$ Inhibitor, Etanercept, in Rat Disc Injury Models
}

\author{
Kazuhide Inage ${ }^{1}$, Sumihisa Orita ${ }^{1}$, Kazuyo Yamauchi ${ }^{1}$, Takane Suzuki ${ }^{2}$, Miyako Suzuki ${ }^{2}$, \\ Yoshihiro Sakuma ${ }^{3}$, Go Kubota ${ }^{1}$, Yasuhiro Oikawa ${ }^{4}$, Takeshi Sainoh ${ }^{5}$, Jun Sato ${ }^{1}$, \\ Kazuki Fujimoto ${ }^{1}$, Yasuhiro Shiga ${ }^{1}$, Koki Abe ${ }^{1}$, Hirohito Kanamoto ${ }^{1}$, Masahiro Inoue ${ }^{1}$, \\ Hideyuki Kinoshita ${ }^{1}$, Kazuhisa Takahashi ${ }^{1}$, Seiji Ohtori ${ }^{1}$ \\ ${ }^{1}$ Department of Orthopaedic Surgery, Graduate School of Medicine, Chiba University, Chiba, Japan \\ ${ }^{2}$ Department of Bioenvironmental Medicine, Graduate School of Medicine, Chiba University, Chiba, Japan \\ ${ }^{3}$ Department of Orthopaedic Surgery, National Hospital Organization Chiba Medical Center, Chiba, Japan \\ ${ }^{4}$ Department of Orthopaedic Surgery, Chiba Children's Hospital, Chiba, Japan \\ ${ }^{5}$ Department of Orthopaedic Surgery, Sainou Hospital, Toyama, Japan
}

\begin{abstract}
Study Design: Experimental animal study.
Purpose: We aimed to determine the optimal dose of a single direct injection of the tumor necrosis factor (TNF)-a inhibitor, etanercept, by using the rat model of degenerative intervertebral disc from injury.

Overview of Literature: The pain-related peptide expression was suppressed in the etanercept (100 $\mu \mathrm{g}$ and 1,000 $\mu \mathrm{g}$ )-administered groups in a dose-dependent manner.

Methods: The neurotracer FluoroGold (FG) was applied to the surfaces of $L 4 / 5$ discs to label their innervating dorsal root ganglion (DRG) neurons $(n=50)$. Ten rats were included in the nonpunctured disc sham surgery control group, whereas the other 40 were included in the experimental group in which intervertebral discs were punctured with a 23-gauge needle. Saline or etanercept (10 $\mu \mathrm{g}, 100 \mu \mathrm{g}$, or $1,000 \mu \mathrm{g}$ ) was injected into the punctured discs ( $\mathrm{n}=10$ for each treatment). After 14 days of surgery, DRGs from L1 to L6 were harvested, sectioned, and immunostained for calcitonin gene-related peptide (CGRP). The proportion of FG-labeled CGRPimmunoreactive DRG neurons was evaluated in all the groups.

Results: There were no significant differences between the puncture+saline group and the puncture+10- $\mu$ g etanercept group $(p>0.05)$. However, a significant decrease in the percentage of FG and CGRP double-positive cells in FG-positive cells was observed in the etanercept (100 $\mu \mathrm{g}$ and 1,000 $\mu \mathrm{g})$-administered groups in a dose-dependent manner $(p<0.05)$.

Conclusions: When a low dose of the TNF- $\alpha$ inhibitor (10 $\mu \mathrm{g}$ of etanercept) was directly administered to the rat intervertebral disc in the rat model of degenerative intervertebral disc from injury, no suppressive effect on the pain-related peptide expression was observed. However, when a higher dose of etanercept (100 $\mu \mathrm{g}$ and 1,000 $\mu \mathrm{g})$ was administered, the pain-related peptide expression was suppressed in a dose-dependent manner.
\end{abstract}

Keywords: Degenerative intervertebral disc; Tumor necrosis factor-alpha; Etanercept; Dose; Optimization

\footnotetext{
Received Nov 16, 2015; Revised Nov 30, 2015; Accepted Nov 30, 2015

Corresponding author: Kazuhide Inage

Department of Orthopaedic Surgery, Graduate School of Medicine, Chiba University,

1-8-1 Inohana Chuo-ku, Chiba 260-8670, Japan

Tel: +81-43-226-2117, Fax: +81-43-226-2116, E-mail: kazuhideinage@yahoo.co.jp
} 


\section{Introduction}

The ingrowth of the pain-mediating nerve surrounding the lumbar vertebral body end plate or annulus fibrosus of the intervertebral disc into the vertebral body end plate and intervertebral disc (nerve ingrowth) is one of the causes of human intervertebral disc back pain [1]. Several cytokines including the neurotrophic factor (nerve growth factor and tumor necrosis factor [TNF- $\alpha]$ ) influence the nerve ingrowth. Above all, TNF- $\alpha$ is one of the factors affecting human intervertebral disc back pain, because TNF- $\alpha$ induces inflammation in the degenerative intervertebral disc and promotes the ingrowth of the pain sensory nerve into the intervertebral disc [2]. Multiple subcutaneous injections of etanercept, a TNF- $\alpha$ inhibitor, are shown to be efficacious for intervertebral back pain, as reported in Europe and the United States. However, the efficacy of etanercept is currently controversial [3,4]. It is thought that the subcutaneous injection of etanercept is inefficacious because its local drug concentration in the intervertebral disc is low [5].

Considering this, we examined the efficacy of a single dose of TNF- $\alpha$ inhibitor ( $100 \mu \mathrm{g}$ of etanercept) that was directly injected into the rat degenerative intervertebral disc. We previously observed a significant increase in the pain-related peptide level in the nerves of rat degenerative intervertebral discs compared with normal discs. In addition, etanercept administration could suppress the increase in the peptide level. We thus reported that a single dose of TNF- $\alpha$ inhibitor with direct injection into the rat degenerative intervertebral disc was efficacious [6]. In our facility, based on the results from these experiments, the TNF- $\alpha$ inhibitor was directly administered as a single dose to patients with intervertebral disc back pain after approval from our clinical study department. We reported that the injection of $10 \mathrm{mg}$ of etanercept into the intervertebral disc was efficacious for human intervertebral disc back pain [7]. However, the appropriate dose of etanercept has not been determined in animal or clinical studies. In the present study, we aimed to determine the optimal dose of a single and direct injection of the TNF- $\alpha$ inhibitor etanercept by using the rat model of degenerative intervertebral disc from injury.

\section{Materials and Methods}

All protocols for the animal procedures were approved by the Ethics Committees of our institutions following the National Institutes of Health Guidelines for the Care and Use of Laboratory Animals (1996 revision).

\section{Retrograde FluoroGold labeling for the detection of DRG neurons}

A total of 50 male Sprague-Dawley rats weighing 250 to $300 \mathrm{~g}$ were used in this study. All the rats were anesthetized with sodium pentobarbital $(40 \mathrm{mg} / \mathrm{kg}$, intraperitoneally) and treated aseptically during all experiments. A midline ventral longitudinal incision was made over the abdomen of each rat, and the L4/5 intervertebral disc was exposed under a microscope. The neurotracer FluoroGold (FG; Fluorochrome, Denver, CO, USA) was applied to the surfaces of all $\mathrm{L} 4 / 5$ intervertebral discs in all the 50 rats to label dorsal root ganglion (DRG) neurons innervating the discs.

\section{Intervertebral disc puncture and etanercept treatment}

After 60 minutes of FG application, 10 of the 50 rats were used as nonpunctured disc sham surgery controls (i.e., the nonpunctured control group: $\mathrm{n}=10$ ), whereas the other 40 were used for the punctured disc experimental model (i.e., intervertebral discs were punctured with a 23 -gauge needle). Each disc was punctured 10 times. Subsequently, $10 \mu \mathrm{g}, 100 \mu \mathrm{g}$, or 1,000 $\mu \mathrm{g}$ of etanercept (total volume: $20 \mu \mathrm{L}$ ) (Takeda Pharmaceutical Co., Osaka, Japan) or $20 \mu \mathrm{L}$ of saline was applied to the punctured discs at the same time point $(\mathrm{n}=10$ for each treatment group: puncture+etanercept [10 $\mu \mathrm{g}, 100 \mu \mathrm{g}$, or 1,000 $\mu \mathrm{g}$ ] groups and the puncture+saline group). The hole was immediately sealed with the cyanoacrylate adhesive to prevent leakage of etanercept or saline, and the skin was closed. This procedure was performed following previously reported methods $[8,9]$.

\section{Dorsal root ganglion resection and fixation}

After 14 days of the surgery, the rats were anesthetized with sodium pentobarbital ( $40 \mathrm{mg} / \mathrm{kg}$, intraperitoneally) and perfused transcardially with $0.9 \%$ saline, followed by $500 \mathrm{~mL}$ of $4 \%$ paraformaldehyde in phosphate buffer (0.1 M, pH 7.4). Next, the DRGs on both sides from the L1 to L6 levels were resected from rats in all the groups; the specimens were immersed in the same fixative solu- 
tion overnight at $4^{\circ} \mathrm{C}$. After storing in $0.01 \mathrm{M}$ phosphatebuffered saline (PBS) containing 20\% sucrose for 20 hours at $4^{\circ} \mathrm{C}$, each ganglion was sectioned at $10-\mu \mathrm{m}$ thickness on a cryostat and mounted on poly-1-lysine-coated slides.

\section{Immunohistochemistry for CGRP}

Endogenous tissue peroxidase activity was quenched by soaking the sections in $0.3 \%$ hydrogen peroxide solution prepared with $0.01 \mathrm{M}$ PBS for 30 minutes. The specimens were then treated for 90 minutes at room temperature in a blocking solution consisting of $0.01 \mathrm{M}$ PBS with $0.3 \%$ Triton X-100 and 3\% skimmed milk. The sections were labeled using a primary rabbit antibody to calcitonin generelated peptide (CGRP; Chemicon, Temecula, CA, USA) diluted 1:1000 in blocking solution, and incubated for 20 hours at $4^{\circ} \mathrm{C}$. To detect CGRP-immunoreactive neurons in the DRGs, the sections were incubated with goat antirabbit Alexa Fluor 488 fluorescent antibody conjugate (1:400; Molecular Probes, Eugene, OR, USA). The sections were examined using a fluorescence microscope, and the number of FG-labeled neurons, total number of CGRP-immunoreactive neurons, and FG-labeled and CGRP-immunoreactive neurons were counted. A randomized sample of 10 areas for each section of DRG was counted.
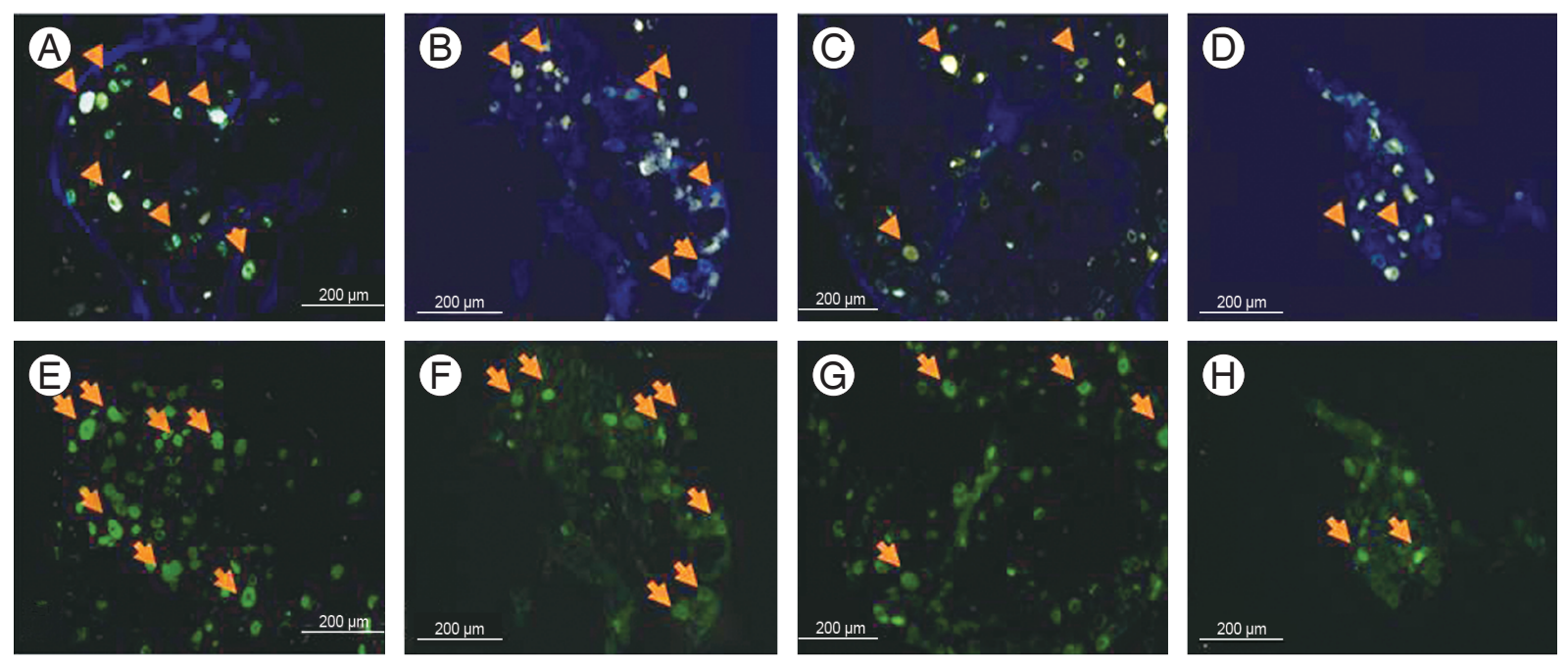

Fig. 1. The arrowheads and arrows indicate the FluoroGold (FG)-labeled calcitonin gene-related peptide (CGRP)-immunoreactive neurons. Immunohistochemistry for CGRP $(\times 100)$. (A-D) FG-labeled neurons. (A) FG-labeled neurons in the puncture+saline group. (B) FGlabeled neurons in the puncture+10- $\mu \mathrm{g}$ etanercept group. (C) FG-labeled neurons in the puncture+100- $\mu \mathrm{g}$ etanercept group. (D) FG-labeled neurons in the puncture+1,000- $\mu \mathrm{g}$ etanercept group. (E-H) CGRP-immunoreactive neurons. (E) CGRP-immunoreactive neurons in the puncture+saline group. (F) CGRP-immunoreactive neurons in the puncture+10- $\mu \mathrm{g}$ etanercept group. (G) CGRP-immunoreactive neurons in the puncture+100- $\mu \mathrm{g}$ etanercept group. (H) CGRP-immunoreactive neurons in the puncture+1,000- $\mu \mathrm{g}$ etanercept group. 


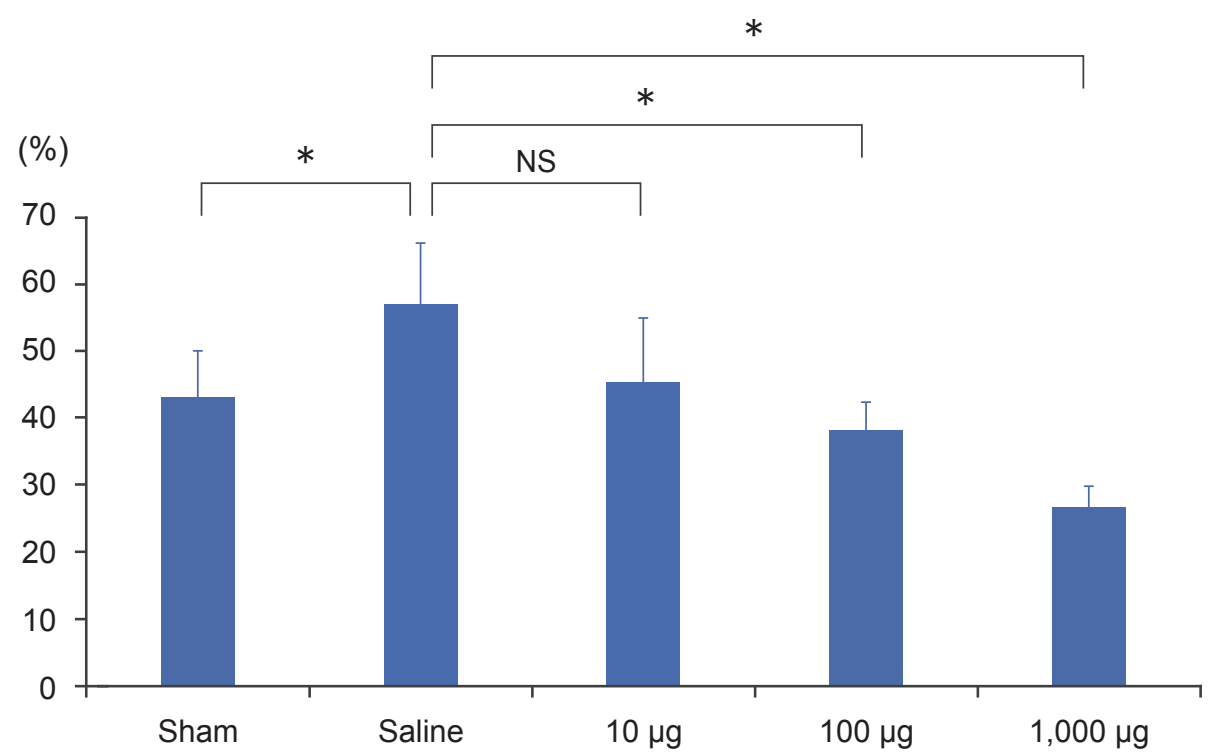

Fig. 2. In the L1-6 dorsal root ganglion, the ratio of FluoroGold (FG)-positive calcitonin gene-related peptide positive cells in FG-positive cells in the nonpunctured sham control, puncture+saline, puncture+10$\mu \mathrm{g}$ etanercept, puncture $+100-\mu \mathrm{g}$ etanercept, and puncture $+1,000-\mu \mathrm{g}$ etanercept groups. NS, not significant. Analysis of variance test. ${ }^{*} p<0.05$.

manner $(p<0.05)$.

\section{Discussion}

In the present study, we observed an increase in the painrelated peptide level in the rat disc puncture model. In addition, when $10 \mu \mathrm{g}$ of etanercept was directly administered as a single dose to the rat intervertebral disc, no suppressive effect on the pain-related peptide expression was observed in the administered group, indicating that a low dose of etanercept was inefficacious. This is consistent with the results previously reported by Cohen et al. [5]. They reported that a single dose of etanercept (0.1-1.5 $\mathrm{mg}$ ) with direct injection into the intervertebral disc of patients with chronic intervertebral disc pain was inefficacious [5]. On the other hand, the pain-related peptide expression was suppressed in the etanercept $(100 \mu \mathrm{g}$ and $1,000 \mu \mathrm{g}$ )-administered groups in a dose-dependent manner. It was reported that the subcutaneous injection of etanercept reduced the disease activity of patients with active rheumatoid arthritis (RA) in a dose-dependent manner [10]. However, the subcutaneous injection of $50 \mathrm{mg}$ of etanercept to RA patients results in a significantly higher risk for adverse events compared to the $25 \mathrm{mg}$ injection. For instance, upper respiratory infection particularly develops 4 times more often for etanercept treated RA pa- tients. Therefore, we think that such a simple subcutaneous dose escalation is unfavorable from a viewpoint considering the possibility of complications [11]. Based on these results, a direct and single administration of a high dose of etanercept at $25 \mathrm{mg}$ and 2.5 times as high as the previous clinical trial study into the intervertebral disc of patients with chronic intervertebral disc pain is currently being tested. The results so far suggest a higher efficacy of etanercept. In addition, we will carefully observe the adverse events such as infections that are associated with the increase in the dose of etanercept.

\section{Conclusions}

When a low dose of the TNF- $\alpha$ inhibitor (10 $\mu \mathrm{g}$ of etanercept) was directly administered to the rat intervertebral disc in the rat model of degenerative intervertebral disc from injury, no suppressive effect on the pain-related peptide expression was observed. However, when a higher dose of etanercept $(100 \mu \mathrm{g}$ and 1,000 $\mu \mathrm{g})$ was administered, the pain-related peptide expression was suppressed in a dose-dependent manner. Based on these results, in our facility, a direct and single administration of a high dose of etanercept $(25 \mathrm{mg}, 2.5$ times as high as the previous clinical trial study) is currently being tested after approval from our clinical study department. 


\section{Conflict of Interest}

No potential conflict of interest relevant to this article was reported.

\section{References}

1. Cavanaugh JM, Ozaktay AC, Yamashita T, Avramov A, Getchell TV, King AI. Mechanisms of low back pain: a neurophysiologic and neuroanatomic study. Clin Orthop Relat Res 1997;(335):166-80.

2. Shinohara H. Lumbar disc lesion, with special reference to the histological significance of nerve endings of the lumbar discs. Nihon Seikeigeka Gakkai Zasshi 1970;44:553-70.

3. Korhonen T, Karppinen J, Malmivaara A, et al. Efficacy of infliximab for disc herniation-induced sciatica: one-year follow-up. Spine (Phila Pa 1976) 2004;29:2115-9.

4. Korhonen T, Karppinen J, Paimela L, et al. The treatment of disc herniation-induced sciatica with infliximab: results of a randomized, controlled, 3-month follow-up study. Spine (Phila Pa 1976) 2005;30:2724-8.

5. Cohen SP, Wenzell D, Hurley RW, et al. A doubleblind, placebo-controlled, dose-response pilot study evaluating intradiscal etanercept in patients with chronic discogenic low back pain or lumbosacral ra- diculopathy. Anesthesiology 2007;107:99-105.

6. Horii M, Orita S, Nagata M, et al. Direct application of the tumor necrosis factor- $\alpha$ inhibitor, etanercept, into a punctured intervertebral disc decreases calcitonin gene-related peptide expression in rat dorsal root ganglion neurons. Spine (Phila Pa 1976) 2011;36:E80-5.

7. Sainoh T, Orita S, Miyagi M, et al. Single intradiscal administration of the tumor necrosis factor-alpha inhibitor, etanercept, for patients with discogenic low back pain. Pain Med 2016;17:40-5.

8. Ohtori S, Takahashi Y, Takahashi K, et al. Sensory innervation of the dorsal portion of the lumbar intervertebral disc in rats. Spine (Phila Pa 1976) 1999;24:2295-9.

9. Ohtori S, Takahashi K, Chiba T, Yamagata M, Sameda $H$, Moriya $H$. Sensory innervation of the dorsal portion of the lumbar intervertebral discs in rats. Spine (Phila Pa 1976) 2001;26:946-50.

10. Moreland LW, Daniel WW, Alarcon GS. The value of the Norgaard view in the evaluation of erosive arthritis. J Rheumatol 1990;17:614-7.

11. Johnsen AK, Schiff MH, Mease PJ, et al. Comparison of 2 doses of etanercept ( $50 \mathrm{vs} 100 \mathrm{mg}$ ) in active rheumatoid arthritis: a randomized double blind study. J Rheumatol 2006;33:659-64. 